\title{
QUANDO A DESTERRITORIALIZAÇÃO VEM DO RIO: A POLUIÇÃO DO RIO GRAMAME NA COMUNIDADE QUILOMBOLA DE MITUAÇU, PB
}

\author{
WHEN DETERRITORALIZATION \\ COMES FROM THE RIVER: THE \\ POLLUTION OF THE GRAMAME RIVER \\ IN THE QUILOMBOLA COMMUNITY OF \\ MITUAÇU, PB
}

\section{Patrícia dos Santos Pinheiro}

E-mail: patriciasantspinheiro@gmail.com

Pós-doutoranda pelo Programa de Pós-Graduação em Antropologia, Universidade Federal da Paraíba (UFPB), bolsista PNPD/Capes.

Orcid: https://orcid.org/0000-0001-5366-3447

Aline Maria Pinto da Paixão

E-mail: aline.ppaixao@gmail.com

Mestre pelo Programa de Pós-Graduação em Antropologia, Universidade Federal da Paraíba (UFPB).

Orcid: https://orcid.org/0000-0001-9642-0445

\section{RESUMO}

A Bacia do rio Gramame, estado da Paraíba, Brasil, é uma das principais fontes de abastecimento da Grande João Pessoa e também de onde muitos ribeirinhos e quilombolas tiram seu sustento. No entanto, modificações causadas por cargas de poluição no rio Gramame têm se tornado recorrentes e se somam ao cenário brasileiro de inquietante frequência de conflitos e eventos que têm na questão ambiental um importante componente. Essas contaminações, que ocorrem por ao menos quatro décadas no Gramame, possuem origem industrial, agrícola e urbana e causam mudanças nas características do rio. Um dos territórios afetados é a comunidade quilombola de Mituaçu, na área rural do município do Conde (PB). Com terras férteis e protegida por rios, especialmente o Gramame, esse rio é mencionado como tendo criado muitas famílias em Mituaçu: ele "protege" a comunidade dos avanços da cidade; é onde tomavam banho; onde aprenderam a nadar, pescar, andar de barco; muitos moradores lembram que outrora a pesca evitava a fome, ao suprir a comunidade com abundância de caranguejos, peixes e camarões. Diante desse quadro, este artigo procura analisar as ressignificações e adaptações deste território, diante (e apesar) do cenário associado em particular à poluição deste rio. Procuramos descrever, entre práticas criativas e memórias, a conformação de sistemas complexos de conhecimento tradicional que se reinventam tendo em vista as mudanças que experimentaram.

Palavras-chave: Território quilombola. Racismo ambiental. Rio Gramame.

\section{ABSTRACT}

The Gramame River Basin, state of Paraíba, Brazil, is one of the main sources for 
the public water supply in Joao Pessoa's metropolitan region and also where many ribeirinhos and quilombolas make a living. However, the modifications caused by the constant loads of pollution in Gramame river have become recurrent and add to the Brazilian scenario of the disquieting frequency of conflicts and events that have in the environmental question an important component. These contaminations, having occurred for at least four decades, have industrial, agricultural and urban origins and cause changes in the characteristics of the river. One of the affected territories is the quilombola community of Mituaçu, in the rural area of the municipality of Conde (PB). With fertile land and surrounded by rivers, especially the Gramame, this watercourse is mentioned as having «raised» several families in Mituaçu: it protects the community from the advances of the city; it is where they learned to swim, to fish, to ride a canoe; many quilombolas remember that fishing once prevented hunger by supplying the community with plenty of crabs, fishes and shrimps. Thus, this work seeks to bring some elements to analyze the re-significances and adaptations of this territory, in the face of (and despite) the scenario associated in particular with the pollution of this river. We seek to describe, among creative practices and memories, the conformation of complex systems of traditional knowledge that reinvent themselves in view of the changes they have experienced.

Keywords: Quilombola territory. Environmental racism. Gramame river.

\section{O CAMINHO QUE LEVOU A MITUAÇU}

Neste artigo, buscamos analisar as ressignificações e adaptações de um território quilombola localizado na zona rural do município do Conde, litoral sul da Paraíba, a comunidade quilombola de Mituaçu, diante (e apesar) do quadro associado em especial à poluição de um importante rio da região, o Gramame. Procuraremos relacionar esse caso com o debate sobre racismo ambiental, assim como os processos de desterritorialização que se desdobraram das modificações que chegaram a Mituaçu pelo rio. Desta maneira, entre práticas e memórias, abordaremos a conformação de complexos sistemas de conhecimento tradicional que se expandem e se relacionam com essas mudanças.

No trajeto até Mituaçu, chegamos principalmente por um caminho: saímos da BR 230 (nos primeiros quilômetros da Rodovia Transamazônica), na cidade de João Pessoa, capital da Paraíba, em direção aos bairros Funcionários II, Grotão e, depois, Colinas do Sul, até nos aproximarmos do bairro Gramame. Durante esse trajeto, vemos casas, prédios, bancas de feira, ruas estreitas apinhadas de gente, ônibus que vão e voltam dos bairros, lojas com todo tipo de bens, carros e mercadorias em carrinhos, condomínios populares que crescem com velocidade. Nesse universo de pessoas, coisas e atividades tão diversas, mas que seguem em um ritmo ininterrupto, vemos a expansão da cidade até suas bordas. Esse ritmo muda quando o asfalto dá lugar a uma estrada de chão, invariavelmente esburacada, com movimento sensivelmente menor.

Dali, com uma grande ladeira na qual há um fluxo menos intenso, mas constante, cruzamos com pessoas, animais, motos e carros que levam materiais a serem comercializados na feira do Grotão, como inhame, feijão, macaxeira, frutas. Após descer a ladeira, chegamos em um ponto crucial: a Ponte dos Arcos, que liga a urbe não muito distante à comunidade de Mituaçu. A firme e bela ponte de concreto do rio Gramame (Figuras 1 e 2), coberta de marcas do tempo, é datada de 1930, precedida por uma ponte de madeira no mesmo local; já a partir de meados do século XIX há menções da reconstrução dessa ponte, como pontua Nascimento Filho (2006). Sendo assim, já presenciou fortes cheias que chegaram a cobri-la parcialmente, como relatam os moradores de Mituaçu, com profundo respeito pela força que o rio possui e que, de tempos em tempos, é revivida nas margens que transbordam, caso do ano de 2019. A ponte é o principal caminho de ligação entre Mituaçu e o mundo. 
Figuras 1 e 2 - A Ponte dos Arcos, no Rio Gramame
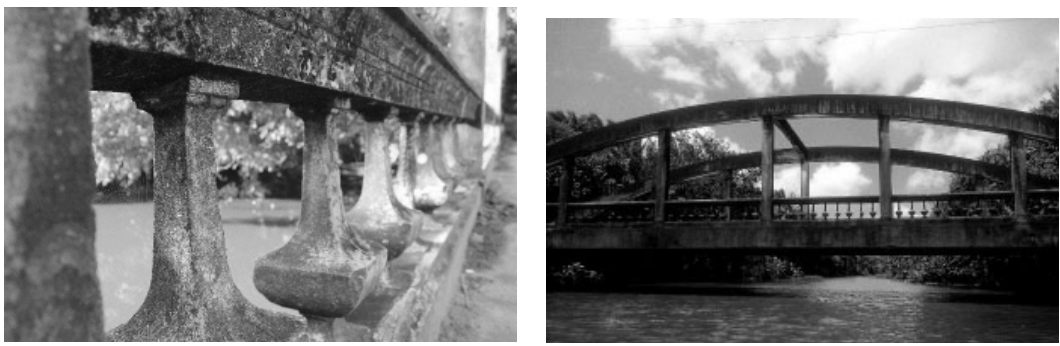

Fonte: acervo do projeto Histórias de Quilombo, 2017.

Mas, antes mesmo de chegar à ponte, já podemos avistar uma parte do mangue, que oscila dependendo da maré. O mangue, tão importante para a comunidade, é guardado - ao menos nas narrativas de tempos remotos - por Comadre Fulozinha e o Pai do Mangue, entidades que habitam e protegem esse emaranhado de árvores, caranguejos, pássaros e outros seres. E assim, a estrada que se segue já não lembra o asfalto deixado para trás há poucos quilômetros de distância. A confluência de sons diminui, o horizonte pode ser vislumbrado de modo singular e, a depender do horário, o pôr do sol domina a paisagem, mesmo que, ao fundo, observem-se pequenos contornos coloridos, que, com o chegar da noite, rememoram-nos a proximidade da cidade pelas luzes que começam a se destacar. Trata-se de uma estrada que, em tempos chuvosos, divide espaço com uma nascente próxima, o que pode inviabilizar temporariamente a passagem de automóveis.

A presença das pesquisadoras em Mituaçu iniciou em momentos e de formas bastante distintas, mas o encontro deu-se no projeto de extensão "Histórias de Quilombo: memórias e identidade coletiva na produção audiovisual da comunidade quilombola de Mituaçu, Conde, Paraíba”, desenvolvido pela Universidade Federal da Paraíba (UFPB) desde 2017 na comunidade, mais especificamente na escola municipal Ovídio Tavares de Morais. Naquele momento, o objetivo do projeto foi instigar reflexões e ações de valorização de práticas e saberes locais a partir do uso de novas possibilidades introduzidas com as tecnologias digitais, vivenciando o uso de ferramentas acessíveis para a elaboração de fotografias e vídeos junto a turmas de EJA (Educação de Jovens e Adultos) e do $5^{\circ}$ ano do ensino básico. Nesse ambiente escolar, iniciaram-se, em julho de 2017, oficinas semanais, acrescidas de vivências de campo. E, dessa percepção, que também dialoga com o método etnográfico, procuramos realizar a produção de materiais audiovisuais.

Esse trabalho propiciou, coma aproximação com a escola, experiências e resultados não previstos, gerados pelo seu viés participativo, que se desdobraram em oficinas diversas ao longo dos anos que se seguiram. De modo a dialogar com as demandas locais por produção de conteúdo, as atividades do projeto voltaram-se para o debate sobre as mudanças no território, sobre memória e sobre conflitos socioambientais, tendo o rio Gramame como central para os moradores. Dentre os inúmeros registros produzidos por estudantes da escola quilombola junto com a equipe da UFPB, o percurso do rio Gramame, as histórias de vida, os seres, os trabalhos de subsistência e a pesca artesanal de caranguejos, peixes e camarões foram temas recorrentes (PAIXÃO et al., 2018).

Os direcionamentos dados pelos estudantes quilombolas (quem entrevistar, quais temas selecionar, quais práticas registrar etc.), a partir de suas experiências como pescadores e/ou agricultores, levaram-nos a priorizar o registro de usos antigos e atuais do rio. Contamos, para tanto, com o relato dos moradores mais velhos da comunidade que tinham ou têm o ofício de pescadores. Também participaram, como entrevistados, produtores e/ou equipe técnica, pessoas que 
foram criadas pelo rio, ou seja, para as quais o rio forneceu sustento alimentar, brincadeiras, local de descanso, entre outros. E, assim, mesmo que nem todos se autodenominem como pescadores, desenvolveram estreita relação com o rio, atualizadas pelas demandas e possibilidades contemporâneas.

Nossos interlocutores, muitos destes também alunos da turma de EJA, participaram da produção de materiais audiovisuais que estão sob os cuidados da escola, sendo dois destes relacionados diretamente ao rio Gramame: um dos ensaios produzidos durante as oficinas, "A vida no rio"; e o vídeo "Gramame, um rio de histórias" (GRAMAME..., 2018). Especificamente no caso do vídeo, sensibilizadas pelos relatos de cargas recorrentes de poluição no rio e pela situação que se configurava como um racismo ambiental, no exato momento em que o mesmo estava sendo finalizado, nós, autoras, recebemos a notícia de mais um evento de poluição no rio Gramame: o vazamento de soda cáustica no rio, que será descrito a seguir. A opção foi de realizarmos um novo registro a ser adicionado ao material original que comporia o vídeo, já em vias de finalização da edição, quando fomos guiadas por moradores de Mituaçu e pescadores, que naquele momento lutavam para obter justiça (PINHEIRO; PAIXÃO, 2018).

Assim, em paralelo ao mencionado projeto de extensão, fomos instigadas a aprofundar também as reflexões sobre os efeitos da poluição no rio em Mituaçu. Neste artigo, fruto dessas reflexões, iniciaremos por uma apresentação do território de Mituaçu, seguida pelo debate sobre racismo ambiental a partir do caso de contaminação do rio Gramame.

\section{MITUAÇU, UM TERRITÓRIO QUILOMBOLA NO NORDESTE BRASILEIRO}

Desde o início da colonização do Nordeste, essa região do litoral brasileiro passou por disputais coloniais principalmente entre holandeses, portugueses e franceses, com alianças estratégicas com povos indígenas. $\mathrm{Na}$ formação do litoral da Paraíba (mas não somente), podem ser mencionados em especial a presença dos Potiguara e dos Tabajara (OLIVEIRA FILHO, 2004). Junto aos indígenas que já ocupavam o que hoje corresponde ao estado da Paraíba, essa formação tornou propicia a incorporação e o refúgio de vários grupos sociais, como negros ex-escravizados e seus descendentes, além de outras pessoas oriundas de classes populares (NASCIMENTO FILHO, 2006; CARVALHO, 2008 apud MURA; PALITOT; MARQUES, 2010), tal qual ocorreu em Mituaçu. Da estreita relação entre indígenas e afrodescendentes nas primeiras gerações de Mituaçu, posteriormente este se consolidou como um território negro (SANTOS, 2011).

Dentre as narrativas de chegada das famílias negras nesse local, que remontam pelo menos até o século XVII, há indicações da presença de cativos que sobreviveram a naufrágios na costa paraibana e que ocuparam o que atualmente corresponde aos municípios do Conde, de João Pessoa e de Pitimbu, sem a indicação de um momento específico. Há também, segundo o trabalho de Santos (2011), relatos dos moradores mais antigos de Mituaçu sobre castigos físicos do tempo do cativeiro, apreendidos de seus ancestrais. Da instalação em um "não-lugar", refúgio pouco visado economicamente, por si parte de um processo de desterritorialização extremo iniciado no período do cativeiro, ao amparo contínuo da população negra, Mituaçu se tornou um espaço de acolhimento e também de conformação de uma identidade coletiva.

Corroborando com as reflexões de Anjos (2004, p. 66), a partir de pesquisa sobre a comunidade quilombola de São Miguel dos Pretos, no Rio 
Grande do Sul, consideramos que nas memórias coletivas há a reprodução, de modo criativo e aberto, de referências históricas comuns que dão suporte às narrativas de fundação do território. Logo, um importante relato que se soma à formação de Mituaçu é o da história de Li, Kaká e Maria Croata (ou Toquarta), irmãs, negras e ex-cativas, das quais descenderia grande parte da comunidade. Essas irmãs teriam trajetórias de vida marcadas por sua ascensão social (como donas de um engenho), seguida de um evento de injustiça que resultou em pobreza extrema, fruto de um roubo de sua fortuna por pessoas brancas pintadas de preto. Ao final, elas teriam superado as adversidades tendo como suporte o rio para a sua sobrevivência. Esses relatos também se conectam com outros dois territórios negros próximos, Guruji e Ipiranga, comunidades que também descenderiam dessas ancestrais (LÉO NETO, 2013, apud MARQUES, 2015; SANTOS, 2011; PAIXÃO, 2014).

De modo mais amplo, as comunidades quilombolas brasileiras se inscrevem em um quadro de desdobramentos da diáspora africana no Brasil em função da escravidão colonial, que ao longo do tempo apresentaram relações conflituosas destes grupos com a sociedade envolvente: ora segregados, ora relegados à mão de obra precarizada, ora alvos da violência policial. Estas singularidades territorializadas, em boa medida, viveram um momento, instigado nacionalmente pela Constituinte de 1988, de multiplicação de grupos locais que reconhecem no cotidiano das suas vidas elementos socioculturais, históricos, políticos e étnicos que os conectam à categoria de remanescentes de quilombos (PINHEIRO, 2015). Vinculam-se ainda a elementos da ancestralidade, da diáspora africana no Brasil e das suas próprias particularidades, variáveis devido às diferenças regionais e às trajetórias de cada grupo.

O processo de reconhecimento instituído coma Constituição de 1988 foi alvo de muitos debates, críticas e traz, de modo geral, além da regularização fundiária, o acesso a direitos sociais básicos e o direito à memória do grupo como elementos centrais. A partir do critério da autoidentificação, previsto na Convenção 169 da Organização Internacional do Trabalho (OIT), que o Brasil ratificou em 2002 (OIT, 2011), há 3.386 registros de comunidades quilombolas certificadas no Brasil, 39 delas na Paraíba. Mituaçu passou pelo processo de autorreconhecimento como remanescente de comunidade quilombola e recebeu, em 2005, o Certificado emitido pela Fundação Cultural Palmares. Mesmo não apresentando conflitos fundiários, a comunidade vem resistindo ao avanço do desenvolvimento urbano e industrial.

Cabe mencionar que intensas discussões envolvem o termo "comunidade tradicional", do qual os povos quilombolas fazem parte. Sem reduzir o "tradicional" a algo estático, relacionado a algum ponto fixo no passado, esses povos mantêm e renovam elementos da ancestralidade, de maneira dinâmica. Pensando nesse processo, trata-se de uma "categoria inclusiva" (O'DWYER, 2018) que não se refere apenas a uma historicidade, mas também incorpora identidades coletivas sociais e políticas, que são mobilizadas e reorganizadas de maneira contínua e expressam uma diversidade de formas de existência compartilhadas entre grupos humanos em suas relações - entre si e com os elementos naturais.

Na configuração das comunidades quilombolas e seus territórios, é importante ressaltar a predominância de formas de solidariedade relacionadas às regras que regem o cotidiano, com delimitações internas e externas reconhecidas socialmente e que também se constituem como fator de identificação (ALMEIDA, 2004; ANJOS, 2004). Tendo em vista uma ampla pluralidade de territórios, Almeida (2008, p. 29) formula o termo "territorialidades específicas" a partir "[...] de diferentes processos sociais de territorialização e como 
delimitando dinamicamente terras de pertencimento coletivo que convergem para um território".

Nossos caminhos mais comuns em Mituaçu, desde 2017, foram a rua principal, que nos leva até a escola Ovídio Tavares de Morais, e a rua do rio, diretamente desembocando no rio Gramame, no Porto de Dedinho (antigamente porto de Biino), onde fica o Canto das Canoas e de onde saíamos em caso de incursões de barco para registros audiovisuais junto aos alunos/quilombolas/ pescadores da turma de Educação de Jovens e Adultos da escola ou para outros eventos, como o Dia da Água. Um de nossos principais narradores, M., descreve suas lembranças de infância sobre os usos desse porto:

\begin{abstract}
"Isso aqui era como se fosse uma pequena praia. E as pessoas também da época costumavam tomar banho no rio. Não tinha a tecnologia que tem hoje. Não era desenvolvido como hoje, que as pessoas têm hoje banheiro em casa, tudo. Naquele tempo, banho era mais no rio. De maneira que era destacado os portos, tinha o porto das mulheres, aqui nessa parte daqui para cá era o porto dos homens" (trecho retirado do vídeo "Gramame, um rio de histórias", 2018).
\end{abstract}

Mituaçu tem limites físicos com João Pessoa, ao norte, Paripe e Guruji, ao sul, Guaxinduba, ao leste e Caxitú, à oeste. A comunidade é praticamente uma ilha delimitada, por um lado, pelo rio Jacoca, na margem que a conecta com Paripe e com o Guruji; e por outro, pelo rio Gramame, na fronteira entre João Pessoa e o Conde - o que acaba por resguardar Mituaçu do crescimento acelerado de loteamentos habitacionais.

Figura 3 - Vista de satélite da comunidade de Mituaçu, que de um lado se localiza próxima de uma das margens do Rio Gramame, e, de outro, do rio Jacoca. Destaque para os loteamentos no canto direito da imagem

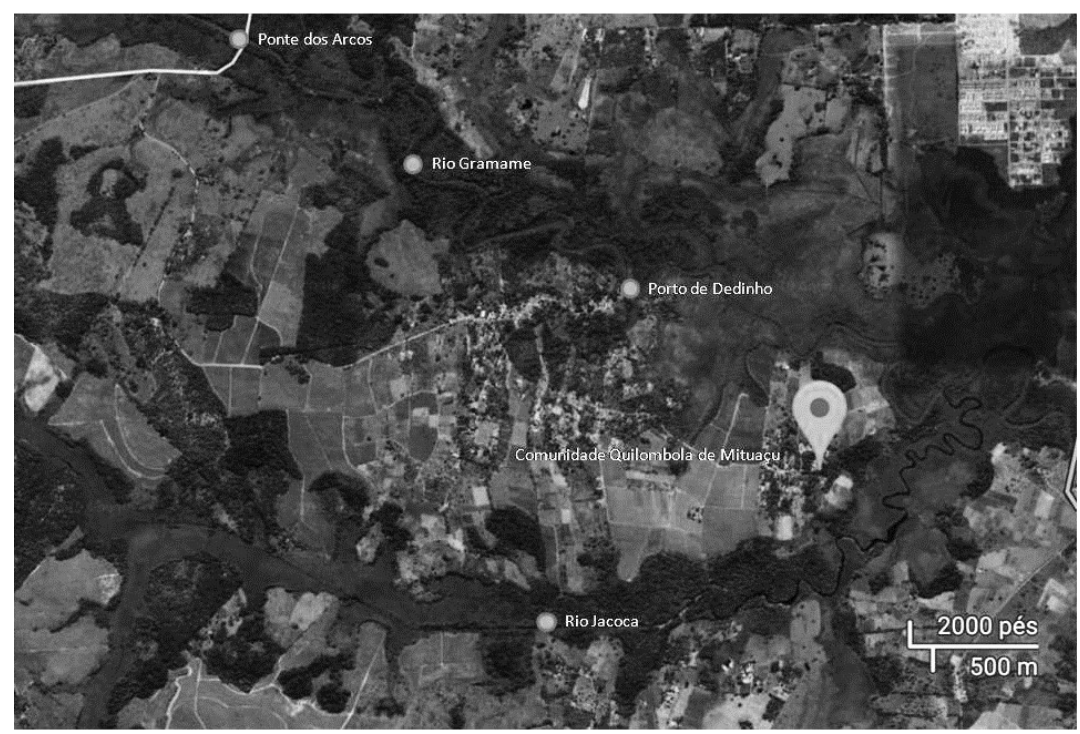

Fonte: Google Maps, acesso em 2019.

A noção de território, porém, como também pontua Diegues (2009), atravessa não somente limites fundiários, mas também aquilo que representa a trajetória de determinado grupo em um local e seu modo de conhecer esse local, o que, em Mituaçu, leva-nos diretamente aos rios que circundam a comunidade. Diegues lembra que, diferente de uma lógica urbano-industrial, as águas têm um papel de produção e reprodução social e simbólica de modos de vida coletivos. Além de saciar as necessidades básicas, as águas e os seres que nelas habitam naturais e sobrenaturais, como Comadre Fulozinha e o Pai do Mangue, presentes na proteção do mangue -também auxiliam na manutenção do equilíbrio local 
e devem ser respeitados. Os rios são mencionados como tendo criado diversas famílias em Mituaçu: é nele que tomavam banho quando não havia banheiro na comunidade; que aprenderam a nadar, a pescar, a andar de barco; do mangue vinha o caranguejo goiamum (variação na pronúncia de "guaiamum").Por ter presenciado inúmeros acontecimentos que marcaram a vida comunitária, diante de suas águas permanecem relatos sobre a memória coletiva, que vão desde os banhos no rio outrora limpo até a referência a lugares de memória nos nomes de cada curva e porto do rio, constituídos coletivamente pelos espaços codificados nos tempos vividos, assim como a cartografia das propriedades próximas a suas margens e as trajetórias daqueles que por ali passaram.

Figura 4 - Mangue no Rio Gramame

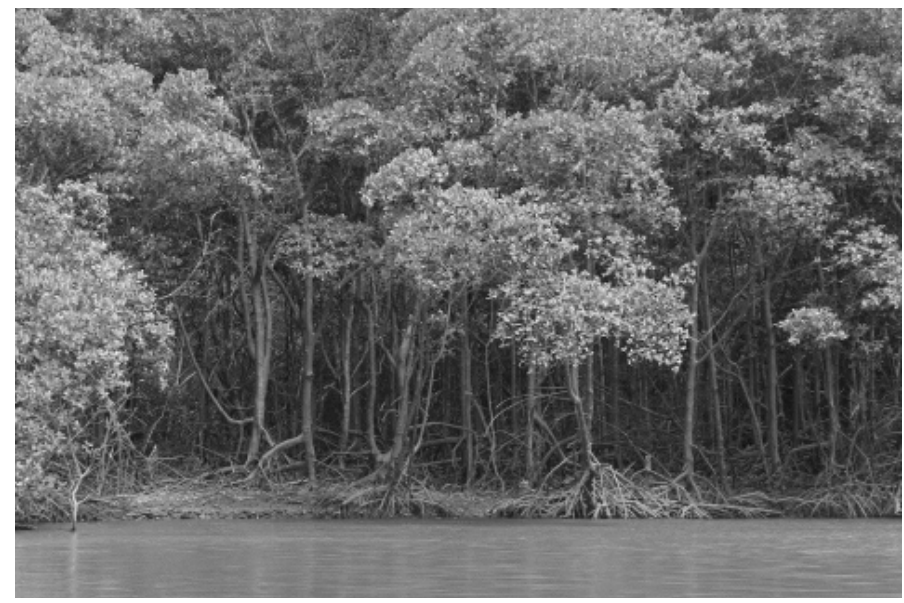

Fonte: acervo do projeto Histórias de Quilombo, 2018.

Outro narrador, J., pescador (ofício que aprendeu com o pai), com 75 anos em 2019, relata sua infância:

\begin{abstract}
"Nós morávamos perto da beira do rio, lá embaixo. Nós tomávamos muito banho no rio. Nós fomos criados com crianças nadando no rio, pegando peixe, brincando de toca dentro de rio, tomando banho. E no início era muito menino, a brincadeira era no rio tomando banho dentro d'água. E nesse tempo dona moça, o rio era escandaloso, esse rio! Só a senhora vendo [...] Esse rio era escandaloso! Uma pessoa para jogar um rebolo de um outro lado desse rio, se não tivesse força não botava. A senhora viu como é que o rio tá agora, aquele riozinho, né? Mas nesse tempo que nós éramos garotos, esse rio além de ter muita correnteza, ser muito veloz, ele era largo. Era um rio muito largo!" (trecho retirado do vídeo "Gramame, um rio de histórias", 2018).
\end{abstract}

O rio se constitui ora como uma entidade, que provê sustento e que todos devem respeitar, ora como um território coletivo, aberto para que todos possam pescar. Não há cercas, mas sim regras sobre o uso coletivo, que, quando são quebradas, causam descontentamento nos demais. Nesse contexto, o controle do rio não está nas mãos de um indivíduo ou grupo doméstico, mas é partilhado através de normas que combinam o uso comum e o privado (ALMEIDA, 2004). Segundo L., pescadora e quilombola, orio é de todos:

"L.: Assim, pego um lado na beira do rio, que não tenha ninguém, não tenha colocado covos, porque tem muita gente que não gosta que a gente coloque no meio dos deles, entendeu? Porque o rio é para todos, como o sol, né? Mas muita gente fica: 'ah, isso ai é meu!'. Não, não é nada, ninguém tem nada. Aí um rapaz disse: 'pronto, [...], pode botar [os covos]'. Aí eu coloquei daquele lado que vocês viram. Eu tenho muitos covos no rio, tenho de um lado, tenho de outro. 
L.: Não, a gente conhece. A minha irmã estava em casa, aí ela disse: 'bota uns cordões, uns laços, para eu ir para os covos, porque se eu vou para os teus covos, eu despesco o dos outros'. Aí eu disse: não, não precisa ir não, eu mesma vou. $O$ povo também despesca os covos da gente. Eu prefiro que despesque, não me importo que despesque não, mas às vezes carregam os covos. Teve um dia que levaram 10 covos meus. Eu tive tanto desgosto, que eu disse, oh, meu Deus, eu não vou mais pescar! Deu vontade de cortar tudinho dentro do rio e não ir mais. Aí fiz outros covos, eu e minha prima [...], sabe? Fez tudo de novo comigo, aí eu botei lá no mesmo canto" (trecho retirado do vídeo "Gramame, um rio de histórias", 2018).

A coleta do camarão é realizada com covos feitos artesanalmente com materiais diversos. Dentro do covo, de um lado há um tampo, com a quenga do coco, e do outro há uma sanga, já no meio há uma tela que retém o camarão após sua entrada, como mostra N., pescadora e quilombola, nas Figuras 5 e 6. Os covos são instalados em árvores na beira do rio, a depender da maré ficam na beira do mangue ou dentro do mesmo, e são visitados de canoa regularmente para despesca, ou seja, para a retirada dos animais que ficaram retidos nos covos. Há covos de inúmeras pessoas no rio, que ficam em locais relativamente flexíveis, apesar da identificação dos espaços, sendo que cada um reconhece os seus.

Figuras 5 e 6 - Despesca dos covos e o detalhe do covo por dentro
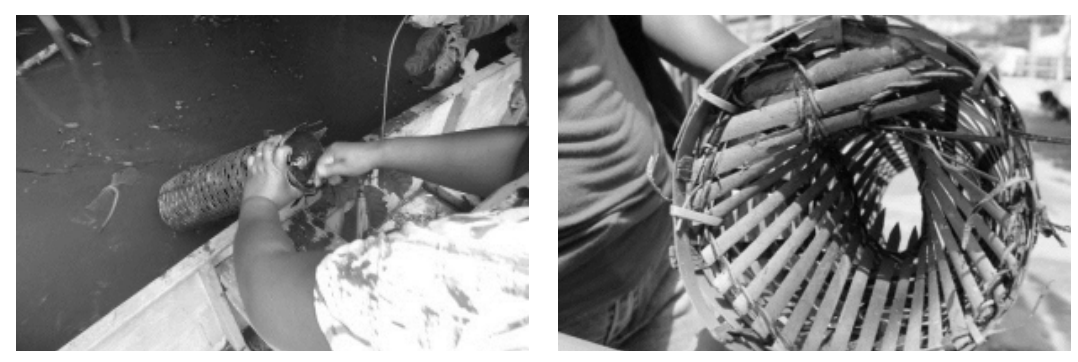

Fonte: acervo do projeto de extensão Histórias de Quilombo (UFPB), 2018.

Além do camarão, armadilhas são usadas para coleta de caranguejos, ratoeiras, que são utensílios de plástico com arame, armadas em áreas propícias, próximas das tocas, deixadas por cerca de 40 minutos no local e, posteriormente, retiradas. Os caranguejos, de diversos tipos, são retirados vivos e amarrados habilmente pelos pescadores, vendidos em feiras livres ou consumidos pelas famílias locais. Cabe ressaltar que é observado o período de reprodução dos animais, para que haja a sua manutenção. Nunes (1998), em um rico trabalho sobre os caranguejeiros de Vitória, no Espírito Santo, salienta que o conhecimento sobre a ecologia e sobre os ciclos do caranguejo são essenciais para manter o equilíbrio da espécie. Um momento sensível, também relatado pelo autor, é o da andada, período que se estende em geral de janeiro a março, no qual os caranguejos fêmeas e machos, orientados pelas luas (cheia e nova) saem dos "buracos" para acasalar, tornando-os mais vulneráveis. Ciclos que são observados e respeitados pelos pescadores de Mituaçu.

Outro momento importante para se compreender esse processo é o período de crescimento do caranguejo, como podemos observar no trecho abaixo, que nos foi relatado por N., nosso guia em todas as incursões de canoa pelo rio Gramame:

"Ele se entoca e começa a trabalhar, começa a trabalhar, botar essa argila para fora. Quando ele bota essa argila para fora que tampa esse 
buraco ele passa três meses sem se alimentar, só a comida que ele comeu, está gordo, aí então ele [pode] passar aqueles três meses. Nesse período ele vai descascar, entendeu. Ele vai tirar aquele casco dele, aí fica mole, ele fica mole. Ai então ele fica debaixo d'água mole com o buraco tapado [...] quando for de três meses por diante ele vai criando um casquinho [...] quando ficar forte o casco, com o casco já resistente ele abre o buraco com uma fome, magro, aí ele começa a comer, se alimentar... Quando abrir o buraco ele vai estar maior, ele cresceu. Ele faz isso para crescer" (entrevista com N., 2017).

Nesse contexto, os conhecimentos locais também funcionam como formas de compreensão das práticas de manejo e de formas locais de regulação dos ecossistemas. A pescaria, por exemplo, é feita com canoas e diferentes tipos de redes. Para todas as situações, é necessário saber a movimentação das marés, a partir da lua, conforme explica detalhadamente J., exímio conhecedor dos ciclos lunares:

\begin{abstract}
"Do rio Gramame nós conhecemos ele de dia à noite. [...]Tem que ter um estudo para saber qual é a maré que vai dar aqui e a maré que vai dar ali. Que ali é alto, quando é maré não vai botar ali porque ali é alto. [...] A maré tem sete dias de grande. Crescendo. E sete dias minguando [...]. Por sete dias se chama maré morta. Ela enche um pouquinho e vaza, não bota, não presta para pescar nada. [...] Aí quando passava aqueles sete dias ele começava, todo dia. Ai com três dias que ela começava a lancear [...], já dava pescaria, já estava entrando no mangue. Aí chegava com sete dias ela já estava esbanjando tudo. Naquelas alturas, enchia para todo lado. A pescaria era assim! Sete dias de maré morta e sete dias de maré grande. Aí nós, como pescador, o giro da gente, quer dizer o prumo nosso são os planetas. A lua é que domina todas as coisas. A lua está saindo a maré está cheia em todo o território brasileiro, não tem o que perguntar. E se a lua está empinada, está seca em todo território brasileiro. [...] Porque a lua ela tem, eu não cheguei a marcar, mas o meu pai dizia, ela tem $75[\ldots]$ segundos de um dia para outro. Se por ventura hoje ela, ela está junto do sol hoje, quando for amanhã ela está mais lá na frente, não é isso aí? Outro planeta não faz isso, mas a lua faz. Todo dia ela anda mais um pouco, todo dia ela anda mais um pouco, pouco mais ela está lá fora, não é? Que é o modo da lua ficar nova e ficar cheia. Não tem? A lua nova e cheia. Quando a lua está nova, aí ela está aqui e o sol está aqui, igual. Igualou está nova. Por que está nova? Porque o sol só consegue iluminar dela somente essa beirinha dela aqui. Porque ela não é iluminada pelo sol? A lua não recebe a luz do sol para ela brilhar? [...] Chama-se: a lua nova. Quando for amanhã, ela já tem andado um pouquinho para frente o sol já pegava mais um pouquinho, depois de amanhã já vai mais outro pouquinho e vai aumentando e chega em um ponto que ela chega de frente com o sol, ela lá e sol cá, aí é cheia. Ela cheia, aquela lua bem bonita. É porque ela está de frente para o sol, o sol pega ela toda normal. [...] É isso aí, a base para a gente pescar é o ponto das luas, tanto no alto mar como no rio. A pescaria é isso aí" (trecho retirado do vídeo "Gramame, um rio de histórias", 2018).
\end{abstract}

A navegabilidade do rio, porém, não é mais a mesma. Além do assoreamento, também a chamada pasta (Eichhornia crassipes), planta aquática que se prolifera em locais com alta carga de matéria orgânica, acumula-se ao longo do leito do rio e impede o trânsito de barcos em alguns pontos antes do rio encontrar a água salgada do mar. 
Figuras 7 - Pescador com a rede

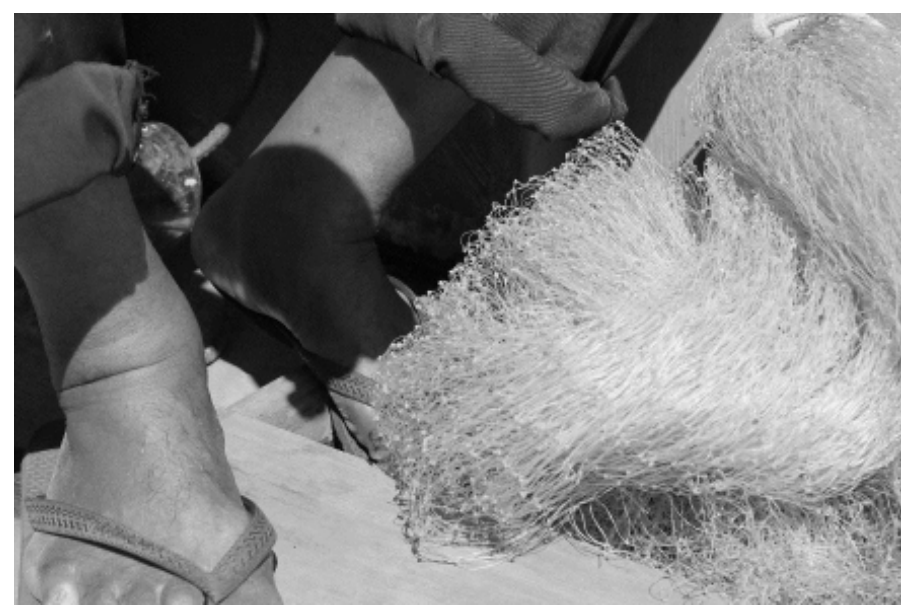

Fonte: acervo do projeto de extensão Histórias de Quilombo (UFPB), 2018.

Os cerca de 900 habitantes de Mituaçu compõem 331 famílias do local, as quais desenvolvem a pesca, a agricultura familiar, a coleta de frutas e o artesanato, itens que são usados para subsistência e comercializados em feiras livres. $\mathrm{O}$ acesso a recursos naturais para a realização de atividades produtivas desse e de muitos dos grupos quilombolas brasileiros foram obtidos em boa medida em situações de adversidade, resistência ou conflito, o que constantemente reforça a coesão e a solidariedade presentes e também as redes de relações sociais que os compõem e que fortalecem o território. Ao mesmo tempo, podem ser vistas áreas significativas de plantações de abacaxi ou de cana de açúcar no interior de Mituaçu, manejadas há anos por um fazendeiro que não faz parte da comunidade.

Atualmente, há cerca de 70 pescadores de Mituaçu cadastrados na colônia de pescadores de Jacumã, a mais próxima da comunidade, porém a relação da população local com o rio vai muito além. Dada a estreita conexão entre as práticas sociais e culturais estabelecidas pela comunidade a partir deste curso d'água, a poluição do rio implica em perda de importantes referências no interior do território, que afetam elementos que conferem significados e orientam suas práticas. Assim, mesmo quando não há uma perda física de terras, há uma perda de controle dos recursos e expressões do território. A poluição, desse modo, é associada a algo que foge à configuração original do rio, que desestruturou modos de vida, que limitou seus usos e, assim, não permitiu a renovação do próprio rio.

Seguindo seu relato, J. aponta uma distinção entre a sua infância e a contemporaneidade, que é a exploração do rio pela agricultura comercial, ponto reforçado por outros moradores:

"Eu lembro que quando eu era garoto e meu pai morava lá no alto, e nesse tempo Mituaçu era coberto de sítio, de mangueiras, era sombrio - as mangueiras morreram tudo. [...] Quando chegava a época do inverno, que chovia, debaixo daquelas mangueiras nascia aqueles olhos d'água, de dentro da terra assim, nascia aqueles olhos d'água. Aí nós corríamos: "bora, bora brincar", nós, meninos, né. Aí tirava o quê? O talo de mamão, da folha do mamão, aqueles talos, e chegava naqueles olhos d'água, enfiava e botava terra [...] Aquela água ... Fazia encanação. [...] Aí as terras ficavam tudo cheia de água, em cima, do alto, dava olho d'água. Mas também não existia esse negócio de irrigação nem de poço artesiano. Mas depois que pegou a existir irrigação e poço artesiano, puxando as águas embaixo, tirando para ceder para os lugares, 
aí a água do rio, se é de ir para o mar, que nem era antigamente, que tinha essa correnteza que eu estou dizendo, ela não vai mais, está indo é por debaixo do chão, para os poços artesianos, para irrigação" (trecho retirado do vídeo "Gramame, um rio de histórias", 2018).

Os relatos, durante o período de registros audiovisuais, indicaram-nos que os conhecimentos sobre o roçado ou sobre a pesca e suas respectivas especificidades não se resumem a interpretar a natureza ou manipulá-la, mas a viver um determinado ambiente em movimento. Um mundo em constante transformação, no qual a delimitação entre os períodos de inverno e verão tem se modificado, as mangueiras foram atacadas por pragas que vieram junto com os "pacotes de modernização" agrícola, por meio da chamada "praga do Recife", e o rio que era escandaloso está assoreado e perdeu profundidade. Nesse mundo, apesar da proteção do rio ainda existir, a aproximação do urbano ou do 'moderno', outrora distantes, trazem também uma determinada concepção de desenvolvimento nem sempre desejada e mesmo os laços comunitários parecem estar sob pressão. Assim, em Mituaçu, os danos ambientais oriundos dessas mudanças são sentidos sensivelmente e demandam novas estratégias para a manutenção do território.

De modo mais amplo, ofensivas que as comunidades quilombolas e ribeirinhas que margeiam o rio Gramame sofrem por conta de uma determinada concepção de desenvolvimento, ligada principalmente ao agronegócio e ao desenvolvimento industrial, prejudicam territórios, seus recursos naturais e a qualidade de vida de seus moradores. Esse debate, na região, envolve desde o fórum permanente em prol do rio Gramame até denúncias feitas pelos moradores, elementos que serão abordados a seguir, conectados com reflexões sobre racismo ambiental.

\section{RACISMO AMBIENTAL: O DESENVOLVIMENTO CORRENTEZA ABAIXO}

O conceito de racismo ambiental remete à desproporção com a qual populações não brancas se deparam com contaminações em sociedades industriais, incorrendo em experiências de exposição a riscos e vulnerabilidades ambientais, seja pelo dano em si, seja pela omissão do poder público ou pela ausência de políticas. Esse debate veio à tona a partir das mobilizações de populações atingidas por incineradores, aterros de lixo industrial etc., e instituições de apoio, em especial nos Estados Unidos, as quais passaram a envolver segmentos acadêmicos e movimentos sociais, como o movimento negro norte-americano (HERCULANO, 2008). Essas articulações, descreve Herculano (2008), levaram ao debate sobre situações de racismo ambiental, que denunciavam, por exemplo, que a escolha dos locais de instalação das indústrias mais poluentes e de descarte de resíduos químicos não era acidental: esses empreendimentos se localizavam justamente em locais de moradia de populações afroamericanas ou ainda de segmentos de imigrantes latino-americanos e povos indígenas.

Os efeitos nefastos desse tipo de empreendimento não se resumem à saúde desses grupos (por si já muito significativos), mas também se interligam a questões sociais, ecológicas e econômicas, aumentando abismos de desigualdade social (PULIDO, 2008). Em acréscimo, Pulido enfatiza que abordar o racismo ambiental auxilia a debater o próprio racismo, dado que não se tratam de casos isolados, mas sim parte de formas estruturais e hegemônicas de racismo que se expressam na conformação de espacialidades, em que há uma 
permissividade maior na contaminação em determinadas áreas e em outras não, como fruto da relação entre diferentes locais, como zonas industriais, periferias e áreas consideradas nobres (PULIDO, 2008).

Cabe destacar que o racismo age desqualificando o outro, a partir de uma crença na superioridade de uma ideia de raça diante de outra, transformando diferenças em desigualdades, com classificações construídas socialmente e conectadas com a formação de um discurso hegemônico sobre superioridade e estruturas de alteridade, com alterações em sua conceituação e seu conteúdo ideológico ao longo dos processos históricos. É, então, necessário refletir sobre essas desigualdades nos danos ambientais que recaem sobre populações de baixa renda, grupos raciais discriminados, etnias e povos tradicionais, populações marginalizadas que acabam sendo naturalizadas (HERCULANO, 2008). Esse contexto de infravaloração de determinados indivíduos não pode ser visto individualmente, sim pelos processos de seleção de elementos de autoexaltação de determinados grupos e de repulsa de outros, com relações históricas e geográficas (HOFBAUER, 2006).

Pulido, que faz uma abordagem a partir da geografia, propõe que se debata o privilégio branco que constitui o racismo, além da dimensão de discriminação, para explicar os padrões ambientais desiguais. A autora, assim, destaca a importância de pensar de modo mais amplo a questão, para além de casos individuais, com destaque para a intencionalidade dos agentes poluidores. Isso não significa que o racismo atue de modo homogêneo em todos os lugares, mas sim, argumenta a autora, há processos socioespaciais de desigualdade que produzem o racismo ambiental (PULIDO, 2008).

Já Herculano situa o racismo ambiental relacionando-o à injustiça ambiental, quando, de modo mais amplo, a um grupo recai maiores danos ambientais do desenvolvimento. No Brasil, com desigualdades sociais e preconceitos tão enraizados, evidentemente de modo distinto do dos EUA, não faltam situações de exposição à poluição, porém, destaca Herculano, muitas vezes estas são tratadas com descaso ou naturalizadas diante de circunstâncias duradouras de péssimas condições de vida. Apesar da organização de diferentes movimentos que lutam para reverter exposições a situações de contaminação e de perda do controle dos recursos ambientais essenciais para manutenção de modos de vida comunitários, estas ainda são recorrentes e permeadas pela violação de direitos básicos:

\footnotetext{
"O desprezo pelo espaço comum e pelo meio ambiente se confunde com o desprezo pelas pessoas e comunidades. Os vazamentos e acidentes na indústria petrolífera e química, a morte de rios, lagos e baías, as doenças e mortes causadas pelo uso de agrotóxicos e outros poluentes, a expulsão das comunidades tradicionais pela destruição dos seus locais de vida e trabalho, tudo isso, e muito mais, configura uma situação constante de injustiça socioambiental no Brasil, que vai além da problemática de localização de depósitos de rejeitos químicos e de incineradores da experiência norte-americana" (HERCULANO, 2008, p. 5).
}

Diante do complexo contexto brasileiro, além dos grupos que recebem diretamente os danos industriais, Herculano (2008) propõe que se expanda esse conceito também para situações de falta de estrutura e saneamento em periferias urbanas, deslocamento compulsório de atingidos por grandes projetos de desenvolvimento (principalmente populações tradicionais e pequenos produtores) e contaminação e degradação ambiental por agrotóxicos. Seus resultados podem ser evidenciados desde a mudança da paisagem até a impossibilidade de reprodução de práticas singulares, culminando em um processo de desterritorialização mencionado por Haesbaert: 
"Na sociedade contemporânea, com toda sua diversidade, não resta dúvida de que o processo de 'exclusão', ou melhor, de precarização socioespacial, promovido por um sistema econômico altamente concentrador é o principal responsável pela desterritorialização" (HAESBAERT, 2006, p. 67).

No caso aqui analisado, o rio Gramame, que protege a comunidade e traz sustento a tantas famílias, no entanto, vem sendo alvo de longo processo de deterioração. Além da retirada de água para irrigação de plantios diversos, como mencionado nos relatos, as relações entre as práticas sociais e culturais estabelecidas pela comunidade a partir deste curso d'água e de seus manguezais têm sido prejudicadas, ao longo do tempo, por poluição industrial, agrícola e urbana que incidem diretamente no seu território e levaram muitos a buscarem empregos fora da comunidade, até mesmo nas indústrias que acabam por poluir o rio.

Figura 8 - Bacia do rio Gramame

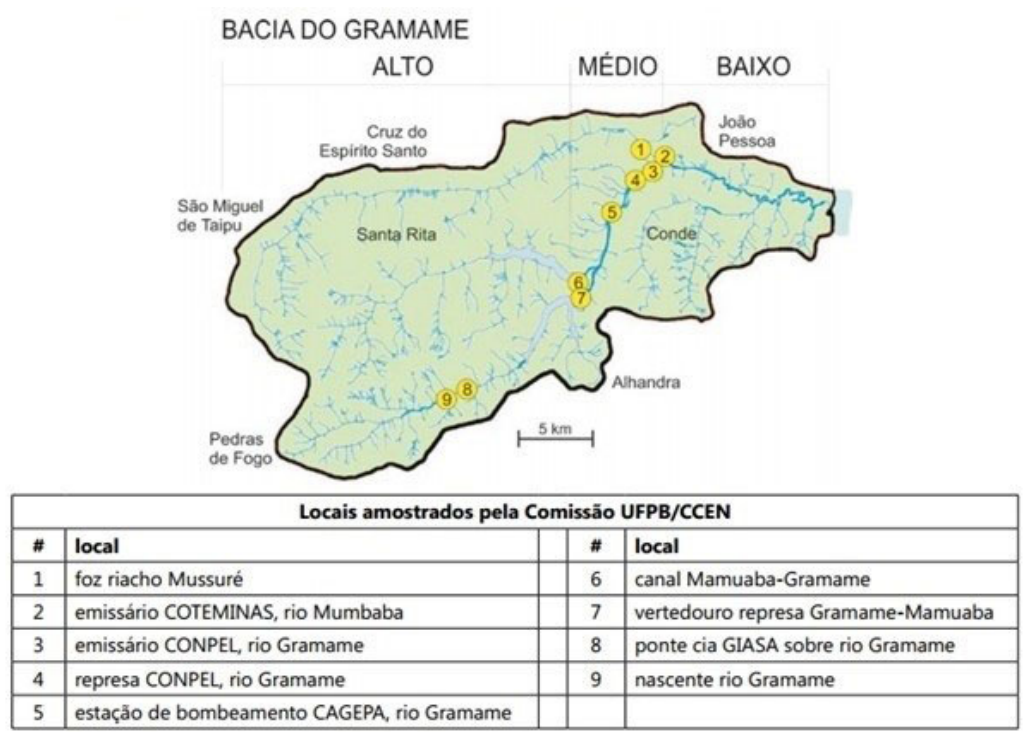

Fonte: Cordeiro, 2014.

Mituaçu está localizada na parte baixa da bacia do rio Gramame, na confluência com o rio Jacoca, já próxima ao mar, desaguando no oceano na Barra de Gramame, um conhecido ponto turístico do Litoral Sul. A bacia hidrográfica do Gramame tem sido monitorada, sob diferentes aspectos, principalmente desde a década de 1980. Segundo o Plano Diretor da bacia, elaborado em 2000, ela é composta pelo rio Gramame e os afluentes Mumbaba, Mamuaba e Água Boa, todos perenes, e drena uma área de 59 mil hectares. Para além da comunidade de Mituaçu, essa bacia é uma das principais fontes de abastecimento da Grande João Pessoa a partir da barragem Gramame-Mamuaba e também de onde ribeirinhos e quilombolas tiram seu sustento.

Em um apanhado dos trabalhos já realizados, Nunes e Garcia (2012) analisaram a poluição industrial na Bacia do Rio Gramame, na comunidade de Mumbaba de Baixo, caracterizando essa situação como um conflito socioambiental, analisado em suas origens, características, correlação de forças entre os atores envolvidos etc. Destacam que a emissão de poluentes industriais nesta bacia hidrográfica se dá desde a década de 1960, quando foi instalado o Distrito Industrial de João Pessoa, nas margens da BR 101.

Dada a recorrência de descargas de poluentes no rio, Ministério Público Federal (MPF) e Ministério Público Estadual da Paraíba (MPPB) 
foram acionados e, em 2008, pesquisadores da UFPB realizaram uma avaliação da qualidade da água por solicitação desses órgãos, para realização de um Termo de Ajustamento de Conduta (TAC), no qual as empresas poluidoras se comprometeriam com medidas de controle (CORDEIRO, 2014). Os dados analisados apontam para a contaminação do rio Gramame por agrotóxicos, como herbicidas, e poluentes vindos das indústrias, com a presença de metais pesados e resíduos de agrotóxicos acima do permitido em lei no rio Gramame. Em especial em Mituaçu foram encontradas altas quantidades de alumínio e sílica nos moradores (CORDEIRO, 2014). Apesar da atuação desses órgãos, o relato dos moradores é de pouca fiscalização sobre esses despejos, que ainda são feitos sistematicamente, e a recorrência da mortandade dos animais que habitam o curso d'água.

Durante uma incursão pelo rio, M., que participou ativamente dos registros audiovisuais, demonstra a preocupação com os efeitos do veneno para os peixes:

\footnotetext{
"Quando vocês vierem aqui um dia, que esse rio tiver poluído, nós vamos fazer questão de trazer vocês aqui para verem. Vocês pegarem a água assim, e cheirar assim e sentir um cheiro horrível. Aqui não, aqui está calmo, mas quando a água tá assim, você vê, os peixes tentando adquirir oxigênio, porque a sujeira que eles colocam dentro do rio, ela tira o oxigênio da água, de maneira que os peixes ficam procurando oxigênio. Aí termina sumindo daqui, aí vão lá para baixo, para a Barra, onde o veneno chega com menos intenção" (trecho retirado do vídeo "Gramame, um rio de histórias", 2018).
}

O Plano diretor da bacia do Gramame (PARAÍBA, 2000) indica que o maior consumidor da água da bacia são os estabelecimentos agrícolas, também com maior área de ocupação. Podem ser mencionadas, ao longo da bacia, grandes plantações de cana de açúcar associadas a indústrias sucroalcoleiras, e também plantações de abacaxi. Corroborando com o Plano Diretor, é recorrente o relato do efeito negativo sentido pelos moradores de Mituaçu com o desenvolvimento da agricultura comercial, por conta do uso excessivo de agrotóxicos, desde herbicidas até carrapaticidas, que acabam sendo escoados pelo rio Gramame.

O Plano cita ainda a presença de mineração (areia, argila, pedra calcária), extração de água mineral, criatório de animais e atividade industrial. Em relação a essa última, atualmente podem ser mencionadas a presença de fábricas de cimento e têxteis. Já atividades turísticas e de lazer se concentram na parte baixa da bacia, na Barra de Gramame.

Como consequência da poluição, o rio Gramame, que outrora tinha abundância de todo tipo de peixe, além de camarões e caranguejos nos mangues em suas margens, hoje apresenta quantidade muito menor desses animais, o que gera a preocupação dos moradores, como L.:

“[...]Eu não vejo uma pessoa de Mituaçu que não lute por esse rio. Pode ser de forma direta ou indireta, mas luta. A gente vê que a poluição tem destruído muito, não só a vegetação. $\mathrm{O}$ número de peixes, quando o pessoal pescava aqui, eu sou testemunha ocular. Peixe de até 11 quilos...hoje é difícil pegar peixe, antigamente era difícil levantar a tarrafa. [..] Nossa esperança e a nossa luta continua sendo: o rio Gramame não pode morrer" (trecho retirado do vídeo "Gramame, um rio de histórias", 2018).

Em 24 de novembro de 2015, foi criado o Fórum Permanente de Proteção ao Gramame, composto pelo MPF, MPE, Ministério Público do Trabalho 
(MPT), Cagepa, UFPB, Secretaria de Meio Ambiente de João Pessoa (SEMAM), Superintendência de Administração do Meio Ambiente (SUDEMA), Instituto Brasileiro do Meio Ambiente (Ibama), ONG Escola Viva Olho do Tempo (EVOT) e indústrias. Dias antes, um episódio de grande repercussão reforçaria a importância de ações concretas no rio Gramame: em 22 de novembro de 2015 a contaminação de empresas instaladas no Distrito Industrial modificou a cor da água, que ficou tingida de azul, com alta mortandade de peixes e camarões (RESENDE, 2015; 2016).

Mais recentemente, em 2016, iniciou-se um diagnóstico socioambiental da bacia, intitulado "Proposta para o diagnóstico ambiental das bacias do Gramame e Abiaí, litoral sul do Estado da Paraíba". A pesquisa prevê identificar as fontes de poluição e analisar alterações nas características físico-químicas e biológicas das águas dos rios, assim como estudos sobre os impactos socioambientais junto às populações ribeirinhas. Estes estudos, em curso, compõem um importante arsenal de pesquisas acadêmicas para o acompanhamento das dinâmicas que envolvem os recursos hídricos na Paraíba.

No ano de 2018, somou-se a esse cenário já preocupante o derramamento de soda cáustica da Companhia de Água e Esgotos da Paraíba (CAGEPA) no rio Gramame, que causou nova mortandade de animais (PINHEIRO; PAIXÃO, 2018), o que prejudicou diretamente Mituaçu e outras comunidades ribeirinhas. A pescadora N. relata como foi a contaminação, na qual grupos socialmente discriminados e vulnerabilizados foram afetados de modo desproporcional:

\begin{abstract}
"N.: O problema desse rio: no dia 9 de fevereiro rompeu-se um cilindro na Cagepa e 40 mil litros de soda cáustica caiu e eles até agora não resolveram nada, até agora estamos esperando, que eles venham aqui fazer alguma coisa por nós. [...] Esse rio é o rio que nós vivemos dele, é de onde a gente tira o nosso sustento para a família. Desde os meus dez anos de idade eu pesco aqui no rio. Os peixes morreram, até urubu que comeu os peixes morreu também. O moço lá em Engenho Velho, colocou o pé na água, ficou todo pipocado o pé dele, muito forte esse produto.
\end{abstract}

Pesquisadoras: Outros bichos morreram também?

N.: Morreram. Cágado, jacaré. Estamos esperando aqui." (trecho retirado do vídeo "Gramame, um rio de histórias", 2018).

A espera era por alguma notícia de ação efetiva de recuperação e também de como proceder sem uma das fontes de renda e de alimento da família, sendo que sequer cestas básicas receberam da prefeitura municipal. Se antes os pescadores trabalhavam na coleta de camarão, caranguejo e peixe, após a contaminação ficaram temporariamente sem essa produção: "agora nós não temos nada no nosso rio", relata a mesma pescadora. Em meados de 2018, a recuperação, lenta, ainda não estava concluída, mas já havia disponibilidade de crustáceos para coleta. 


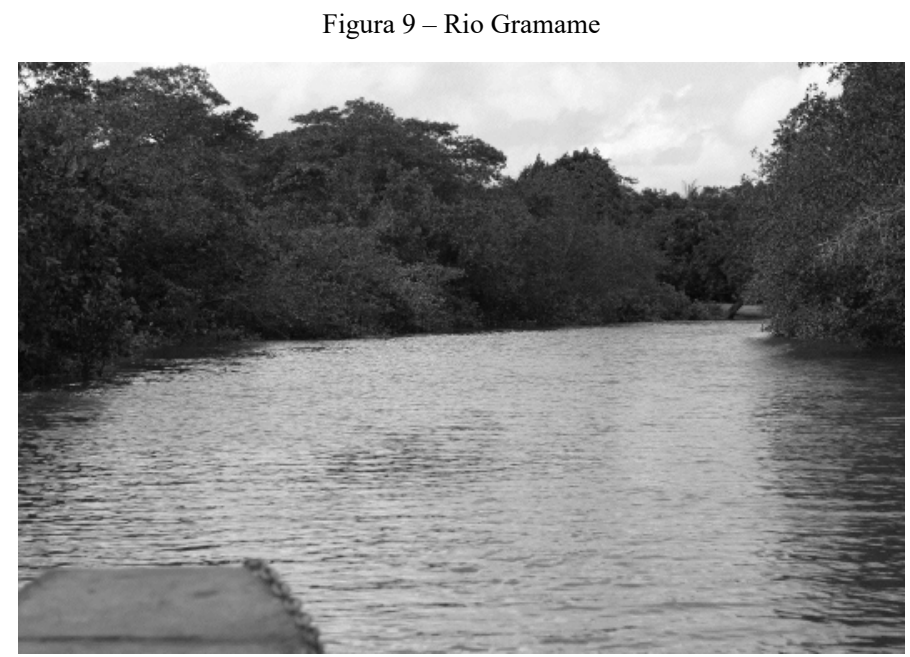

Fonte: acervo do projeto de extensão Histórias de Quilombo (UFPB), 2017.

No dia do vazamento, no início da tarde, a comunidade foi alertada pela Defesa Civil Municipal e Secretaria de Meio Ambiente do município do Conde que evitasse qualquer contato com a água. Segundo o informe, divulgado em redes sociais, "O vazamento aconteceu por conta do rompimento de um cilindro que armazenava o componente na estação de tratamento da Companhia de Água e Esgotos da Paraíba (Cagepa), localizada no município de Conde".

Inicialmente, a água adquiriu tons avermelhados e passou a ter um cheiro forte, os peixes, sem ar, buscavam oxigênio na superfície da água, até morrerem, situação que durou três dias. Além destes, camarões e outros animais apareceram mortos. Passadas duas semanas do ocorrido e diversos dias de chuva intensa que aumentaram a vazão da água, o rio permanecia impróprio para qualquer atividade e os pescadores ainda não podiam voltar a suas atividades: "não tem o que fazer no rio", diziam. O destaque e espanto eram que mesmo urubus, considerados animais muito resistentes, após o derramamento também teriam morrido. Os animais que sobreviveram pareciam fracos, caso dos camarões, que morriam logo após sua retirada da água, fato incomum relatado pelos pescadores.

Figura 10 - Registro de peixes mortos, feito por pescadores um dia após o vazamento de soda cáustica. 2018

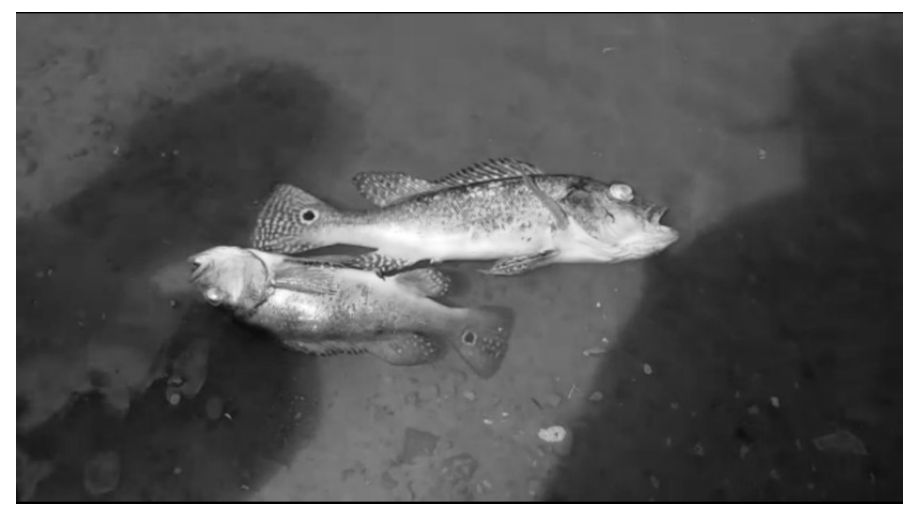

Além da negligência causadora do próprio evento, relata-se que, sem um manejo adequado após a contaminação, houve mortandade generalizada de animais que vivem direta ou indiretamente do rio e a água chegou a um $\mathrm{pH}$ de 0 , agravando a dramática situação. Foi utilizado sulfato de alumínio na tentativa de corrigir a contaminação, o que acabou por piorá-la e ao fim "os peixes se desmanchavam", como relata a mesma pescadora. Mituaçu, assim como Enge- 
nho Velho, são umas das principais localidades afetadas por essa contaminação, dada sua estreita relação com o rio, mas, para os órgãos oficiais, a preocupação se restringiu ao local de retirada de água para o abastecimento da Grande João Pessoa, que não teria sido contaminado.

Apesar da cobertura da mídia indicar a regularização da situação, o relato dos pescadores é outro. Alguns órgãos estiveram na comunidade, a pedido do MPF, fazendo coleta de água para análises e informaram aos quilombolas já estarem efetuando tratamentos de remediação para neutralizar a soda cáustica e também alguns cadastramentos de pescadores da comunidade foram realizados. A multa foi estabelecida pelo Ibama, que fez vistorias e análises de água no rio, no valor de 12 milhões de reais (REDAÇÃO, 2018). A Cagepa, porém, contesta que houve efeitos negativos significativos, e posteriormente indicou que de fato haviam sido derramados "apenas" 8 mil litros de soda cáustica destacado (ROSA, 2018). A Sudema, por sua vez, teria informado que fará a recomposição de fauna, após uma mínima recuperação das águas. Reuniões foram feitas, os pescadores e quilombolas buscaram a Cagepa e os órgãos responsáveis, mas a grande maioria ainda não havia recebido qualquer ressarcimento ou sequer uma ajuda imediata, com exceção de pescadores da localidade de Engenho Velho, no município de João Pessoa, que receberam cestas básicas da prefeitura daquele município.

Após esse evento, os estudos seguem sendo realizados e compartilhados no âmbito do Fórum Permanente. Em 2018, foram apresentados, em audiências públicas, trabalhos que indicam a presença de cianotoxinas e de veneno agrícola, como glifosato, nos peixes do rio Gramame, enfatizando a necessidade de dar continuidade aos estudos sobre a contaminação do rio (PARAÍBA, 2018).

Como fica explícito ao falar de Mituaçu e do rio Gramame, o gerenciamento (que incluiria uma possível prevenção e mitigação de efeitos) da poluição gerada pelas técnicas agropecuárias e industriais utilizadas por diferentes emissores envolve também aspectos políticos e econômicos, não apenas técnico-científicos. Assim, a presença das tecnologias, das mais complexas às mais elementares, possibilita e confirma práticas sociais. Nesse caminho, Benakouche (1999) se contrapõe à ideia de impacto, largamente utilizada por seu apelo dramático e ampla aceitação, capaz de traduzir as incertezas da sociedade moderna. Ela argumenta que, junto com essa ideia, há uma posição de exterioridade intrínseca (impacto do ser humano sobre a natureza), que dicotomiza sociedade e tecnologia e simplifica o complexo processo de determinação e controle humano sobre os ditos impactos. Além disso, essa ideia não dá conta da forma desigual com a qual as transformações ambientais chegam aos mais distintos grupos sociais, como debatido a partir da ideia de racismo ambiental.

\section{ALGUMAS CONSIDERAÇÕES}

As comunidades quilombolas brasileiras passaram por sucessivas tentativas de dissolução e desterritorialização, ocasionadas pelas alterações em matrizes produtivas locais e regionais, acompanhadas da sistemática desvalorização das práticas tradicionais. É nesse contexto que acontecem processos de exxodo rural e saberes produtivos tiveram seu desenvolvimento comprometido, sendo que alguns permanecem somente na memória dos mais velhos. Por outro lado, atualmente a problematização desse histórico de estigmatização tem possibilitado novas reflexões teóricas e metodológicas sobre esses conhecimentos e práticas tradicionais que trazem possibilidades epistêmicas e ontológicas diversas. 
Confrontando-se com as incertezas contemporâneas, quando vinculadas a tecnologias emergentes e ao próprio desenvolvimento sob o aspecto da modernidade, a análise da incidência de poluição se coloca na ordem do dia. E, apesar de sua importância, o rio Gramame ainda é alvo de despejos não tratados de indústrias de grande porte que se instalam ao longo de sua bacia, do escoamento de agrotóxicos de lavouras e de outras atividades que afetam diretamente a vida aquática e as populações próximas, como já detalhado. Com isso, os danos de empreendimentos "modernos" e a ausência de ações adequadas para evita-los, como uma fiscalização efetiva, recaem de modo mais intenso sobre alguns grupos específicos, em especial aqueles que possuem sua sobrevivência e modos de vida associados ao ambiente e ao manejo dos elementos do seu território, como em Mituaçu, que, apesar de tão próximo da cidade, manteve resguardados seus sítios sempre que possível.

Esses fatores relacionados ao racismo ambiental, combinados ou não, acabam por gerar modificações não desejadas em suas formas de organização social e gestão dos recursos naturais, e essas populações acabam sendo impelidas a se deslocar ou permanecer em condições precárias. Assim, veem seus territórios se tornarem as chamadas "zonas de sacrifício", onde é permitida a degradação em nome do desenvolvimento econômico. Como se fosse um espaço vazio, o racismo ambiental invisibiliza populações que possuem imbricada relação com os elementos que manejam no interior do território. Esse processo nos permite refletir sobre a hierarquização baseada em forças econômicas e políticas nas relações socioambientais que ignora a magnitude dos efeitos imputados a determinadas comunidades, já vulnerabilizadas ou alvo de preconceitos e estigmatização.

Atentando para o processo como um todo, é preciso observar a falta de espaços para a atuação quilombolanas tomadas de decisão que incidam sobre seu território, a falta de diálogo e de disseminação de informações sobre soluções concretas, entre outros fatores cruciais para uma real modificação ou mitigação das fontes de poluição que incidem sobre a bacia do rio Gramame.

\section{BIBLIOGRAFIA}

ALMEIDA, Alfredo Wagner B. de. Terra de quilombo, terras indígenas, "babaçuais livre", "castanhais do povo", faxinais e fundos de pasto: terras tradicionalmente ocupadas. 2. ed. Manaus: PGSCA-UFAM, 2008.

. Terras tradicionalmente ocupadas: processos de territorialização e movimentos sociais. Revista Brasileira de Estudos Urbanos e Regionais, v. 6, n. 1, maio 2004, p. 9-32.

ANJOS, José Carlos G. dos. Identidade étnica e territorialidade. In:

SILVA, S. B. (org.). São Miguel e Rincão dos Martimianos: ancestralidade e territorialidade negra. Editora da UFRGS. Porto Alegre, p. 63-118, 2004. BENAKOUCHE, Tamara. Tecnologia é sociedade: contra a noção de impacto tecnológico. Cadernos de Pesquisa, n. 17, set. 1999.

CORDEIRO, Tarcísio. O que você precisa saber sobre a água de João Pessoa. João Pessoa: Ideia, 2014. CD Rom.

DIEGUES, A.C. 2009. Água e cultura nas populações tradicionais brasileiras. In: W. C. RIBEIRO (org.). Governança da água no Brasil: uma visão interdisciplinar. São Paulo: Annablume.

GRAMAME, um rio de histórias. Direção: Patrícia Pinheiro. Produção: Projeto Histórias de Quilombo e Escola Ovídio Tavares de Morais. João Pessoa, 2018 
(21m23s). Disponível em: https://www.youtube.com/watch?v=sg9iLI05dtg. Acesso em: 01 out. 2019.

HAESBAERT, Rogério. O Mito da Desterritorialização: Do Fim dos Territórios à Multiterritorialidade. Rio de Janeiro: Bertrand Brasil, 2011. 396 p.

HERCULANO, Selene. O Clamor por Justiça Ambiental e Contra o Racismo Ambiental. INTERFACEHS - Revista de Gestão Integrada em Saúde do Trabalho e Meio Ambiente, v. 3, n. 1, Artigo 2, jan./ abril 2008. Disponível em: http://www.interfacehs.sp.senac.br/BR/artigos.asp?ed=6\&cod_artigo=113. Acesso em: 13 jun. 2018.

HOFBAUER, Andreas. Uma história de branqueamento ou o negro em questão. São Paulo: Editora Unesp, 2006.

MARQUES, Amanda C. Nascimento. Fronteira étnica: Tabajara e comunidades negras no processo de territorialização do litoral sul paraibano. 2015. 369 f. Tese (Pós-Graduação em Geografia) - Universidade Federal de Sergipe, São Cristóvão, 2015.

MURA, Fabio; PALITOT, Estêvão; MARQUES, Amanda. Relatório de fundamentação antropológica para caracterizar ocupação territorial dos Tabajara no Litoral Sul da Paraíba. Instrução Técnica Executiva no 34/DAF/2009. João Pessoa, 2010.

NASCIMENTO FILHO, Carmelo R. do. A fronteira móvel: os homens livres pobres e a produção do espaço da mata sul da Paraíba (1799-1881). Dissertação (Mestrado em Geografia) - Centro de Ciências Exatas e da Natureza, Universidade Federal da Paraíba, João Pessoa, 2006.

NUNES, Edilon Mendes; GARCIA, Loreley Gomes. Sociedade e natureza: conflito territorial de poluição industrial da bacia do Rio Gramame-Mumbaba - PB. Soc. nat. [online]. v. 24, n. 2, p. 255-266, 2012.

NUNES, André Gustavo Alves. Os argonautas do mangue: uma etnografia visual dos caranguejeiros do município de Vitória - ES. Dissertação (Mestrado em Multimeios). Instituto de Artes, Universidade Estadual de Campinas (UNICAMP), 1998.

O'DWYER, Eliane Cantarino. Os antropólogos, as terras tradicionalmente ocupadas e as estratégias de redefinição do Estado no Brasil. Rev. Antropol, v. 61 n. 1, p. 33-46, USP, 2018.

OIT (Organização Internacional do Trabalho). Convenção no 169 sobre povos indígenas e tribais e Resolução referente à ação da OIT. Brasília: OIT, 2011.

OLIVEIRA FILHO, João Pacheco. A viagem da volta: etnicidade, política e elaboração cultural no Nordeste indígena. 2. ed. Rio de Janeiro: Contra Capa, 2004.

PARAÍBA, Procuradoria da República na. Audiência sobre rio Gramame aborda presença de cianotoxina e agrotóxico em reservatório que abastece João Pessoa (PB). Disponível em: http://www.mpf.mp.br/pb/sala-de-imprensa/ noticias-pb/audiencia-sobre-preservacao-do-rio-gramame-abordara-presenca-de-cianotoxinas-e-agrotoxico-em-reservatorio-que-abastece-a-capital. Acesso em: 16 dez. 2018.

PAIXÃO, Aline Maria P. da. "Aqui todo mundo é parente": dinâmica territorial, organização social e identidade entre os quilombolas de Mituaçu, PB. Monografia (Graduação em Antropologia). Universidade Federal da Paraíba (UFPB), Rio Tinto, 2014.

.PINHEIRO, Patrícia S.; GOLDFARB, Maria P. L.; MOURA, Natália

F. Histórias de Quilombo: Memórias e identidade coletiva na produção audiovisual da comunidade quilombola de Mituaçu, Conde/PB In: IV Semana de Antropologia do PPGA/UFPB, 2018, João Pessoa. Anais da IV Semana de Antropologia do PPGA/UFPB. João Pessoa: Universidade Federal da UFPB, p. 366-369, 2018. 
PARAÍBA - Secretaria Extraordinária do Meio Ambiente, dos Recursos Hídricos e Minerais - SEMARH. Plano diretor de recursos hídricos da bacia do rio Gramame, SCIENTEC, João Pessoa/PB: 2000. Disponível em: http:// www.aesa.pb.gov.br/aesa-website/documentos/estudos-pro-agua/. Acesso em: 01 fev. 2017.

PINHEIRO, Patrícia dos S. Políticas de Identificação: Dinâmicas de reconhecimento identitário de comunidades negras rurais no sul do Brasil em um contexto de relações interétnicas. 2015. 226 p. Tese (Doutorado em Ciências Sociais em Desenvolvimento, Sociedade e Agricultura). Instituto de Ciências Humanas e Sociais, Universidade Federal Rural do Rio de Janeiro, Rio de Janeiro, RJ. 2015.

. PAIXÃO, Aline Maria P. da. Vazamento de soda cáustica no rio Gramame afeta ribeirinhos e quilombolas do litoral sul da Paraiba. Racismo Ambiental. 7 de março de 2018. Disponível em:https://racismoambiental.net. br/2018/03/07/vazamento-de-soda-caustica-no-rio-gramame-afeta-ribeirinhos-e-quilombolas-do-litoral-sul-da-paraiba/. Acesso em: 7 mar. 2018.

PULIDO, Laura. Rethinking Environmental Racism: White Privilege and Urban Development in Southern California. Annals of the Association of American Geographers, v. 90, n. 1 (mar., 2000), p. 12-40.

RESENDE, André. Rio na Paraíba muda de cor após receber água poluida, diz pescador. Jornal Paraíba. 24 nov. 2015. Disponível em: http:/g1.globo.com/pb/ paraiba/noticia/2015/11/rio-na-paraiba-muda-de-cor-apos-receber-agua-poluida-diz-pescador.html. Acesso em: 06 jan. 2019.

. Pesquisador alerta para colapso no abastecimento de água na Paraiba. G1 PB. 10/01/2016.Disponível em: http://g1.globo.com/pb/paraiba/ noticia/2016/01/pesquisador-alerta-para-colapso-no-abastecimento-de-agua-na-paraiba.html. Acesso em: 06 jan. 2019.

ROSA, Joana. MPF aguarda relatório do Ibama para iniciar investigação sobre soda cáustica no rio Gramame. Jornal da Paraíba, fev. 2018. Disponível em: http://www.jornaldaparaiba.com.br/vida_urbana/mpf-aguarda-relatorio-ibama-para-iniciar-investigacao-sobre-sonda-caustica-no-rio-gramame.html. Acesso em: 06 jan. 2019.

REDAÇÃO, da. IBAMA multa Cagepa em R\$ 12 milhões por vazamento no rio Gramame; órgão diz que vai recorrer. Jornal da Paraíba, fev. 2018. Disponível em: http:/www.jornaldaparaiba.com.br/vida_urbana/ibama-multa-cagepa-em-r-12-milhoes-por-vazamento-no-rio-gramame-orgao-diz-que-vai-recorrer. html. Acesso em: 11 jul. 2018.

SANTOS, Glauciê Pereira dos. O povo negro e o vôo para a liberdade: Comunidade Quilombola De Mituaçu (PB-Brasil) Séculos XVII-XXI. Universidade Federal da Paraíba, Centro de Ciências Humanas, Letras e Artes, Programa PEC/MSC/MDA/ INCRA/PRONERA/UFPB, Departamento de História. João Pessoa-PB, 2011. 